\title{
Use of discriminant analysis based on echocardiography for classification of congestive heart failure in dogs with myxomatous mitral valve disease
}

\author{
[Utilização da análise discriminante baseada na ecocardiografia para classificação de insuficiência \\ cardíaca congestiva em cães com degeneração mixomatosa da valva mitral] \\ A.C. Silva ${ }^{1}$, R.A.L. Muzzi ${ }^{1 *}$, L.A.L. Muzzi ${ }^{1}$, D.F. Ferreira ${ }^{1}$, G. Oberlender $^{1}$, \\ M.S. Oliveira ${ }^{1}$, R.B. Nogueira ${ }^{1}$, L.B. Ticle ${ }^{2}$ \\ ${ }^{1}$ Universidade Federal de Lavras - UFLA - Lavras, MG \\ ${ }^{2}$ Hospital Vaz Monteiro - Lavras, MG
}

\begin{abstract}
Mixomatous mitral valve disease (MMVD) is one of the most common cardiac abnormalities in dogs and humans that can lead to cardiac heart failure (CHF). Its diagnosis remains based on echocardiography and clinical signs. However, the early diagnose of MMVD can contribute to a better prognosis and avoid CHF. The aim of this study was to evaluate the clinical, radiographic and echocardiographic presence of CHF in dogs with MMVD in combination with a statistical model as a mathematical tool. For this purpose, dogs were divided into three groups (healthy; MMVD without CHF; and MMVD with CHF), according the clinical, radiographic and echocardiographic evaluation findings. Thus, linear discriminant functions were obtained by analyzing the variables weight, body surface area, aortic diameter, the ratio of the left atrium/aortic diameter, the ratio between the mitral regurgitation jet area and the left atrial area, vena contracta diameter and mitral valve proximal isovelocity surface area. Then, mathematical equations were established for each group of dogs. Statistical functions obtained in this study enabled to classify the dogs, regarding the presence of CHF with a probability of correct classification of $90.4 \%$. Thus the statistical model demonstrated that it could be used as an auxiliary method for identifying CHF in dogs with MMVD.
\end{abstract}

Keywords: canine, cardiac disease, statistical model, vena contracta

\section{RESUMO}

A doença mixomatosa da valva mitral (DMVM) é uma das alterações cardíacas mais comuns em cães e humanos, a qual pode levar à insuficiência cardíaca congestiva (ICC). O diagnóstico dessa alteração ocorre com base principalmente no exame ecocardiográfico e na presença de sinais clínicos. No entanto, o diagnóstico precoce da DMVM pode contribuir para um melhor prognóstico e evitar o desenvolvimento de ICC. Assim, o objetivo do presente estudo foi avaliar a presença de ICC em cães com DMVM, por meio de exames clínico, radiográfico e ecocardiográfico em combinação com um modelo estatístico. Para este propósito, os cães foram divididos em três grupos (sadios; DMVM sem ICC; e DMVM com ICC), de acordo com os achados dos exames realizados. Então, as funções lineares discriminantes foram obtidas por meio da análise das variáveis peso; superfície de área corporal; diâmetro aórtico; relação entre o diâmetro do átrio esquerdo e aórtico; relação entre a área do jato regurgitante mitral e a área do átrio esquerdo; diâmetro da vena contracta e área da isovelocidade proximal mitral (PISA). As equações matemáticas foram estabelecidas para cada grupo de cães e demonstraram ser possível classificar os animais de acordo com a presença de ICC, com uma probabilidade de classificação correta de 90,4\%. Diante disso, o modelo estatístico poderia ser uma ferramenta auxiliar para a identificação de ICC em cães com DMVM.

Palavras-chave: caninos, doença cardíaca, modelo estatístico, vena contracta

Recebido em 24 de abril de 2013

Aceito em 10 de junho de 2014

*Autor para correspondência (corresponding author)

E-mail: ralmuzzi@dmv.com.br 


\section{INTRODUCTION}

Mitral valve disease (MVD) is one of the most common cardiac abnormalities in dogs (Olsen et al., 2003; Atkins et al., 2009) as well as in humans (Enriquez-Sarano et al., 2009). The cause of MVD is still unknown, although a genetic predisposition is noted in some breeds such as Cavalier King Charles spaniels. Senility is also a predisposing factor, especially in small breed animals (Hyun, 2005; Atkins et al., 2009, Lewis et al., 2011; Borgarelli and Buchanan, 2012). There is a higher prevalence in males, which are generally affected at a younger age than females (Borgarelli et al., 2004; Borgarelli and Häggström, 2010).

The thickening of the leaflets and consequent inadequate coaptation result in mitral valve insufficiency, with regurgitation into the left atrium (LA) during systole. This regurgitation can be detected during physical examination by auscultation of a left apical systolic murmur (Ljungvall et al., 2009; Lewis et al., 2011).

The disease has a slow progression over the years and in many cases can lead to the appearance of signs of congestive heart failure (CHF) (Abbott, 2008; Borgarelli et al., 2008; Häggström et al., 2009; Lewis et al., 2011). Development of CHF worsens the prognosis, so an early diagnosis should assist in appropriate clinical management (Schober et al., 2010). An increase in cardiac chamber size as a consequence of mitral regurgitation (MR) is considered a negative prognostic sign (Carlsson et al., 2009).

Currently, methods for identifying the presence or absence of CHF in dogs with MVD are based on clinical evaluation of the patient, radiographic examination and echocardiography. Although this approach may be influenced by factors such as observer experience (Atkins et al., 2009), it is based on techniques that are widely available (Muzzi et al., 2003). In a recent consensus statement, the American College of Veterinary Internal Medicine proposed that the traditional classification of heart failure (I, II, III, IV) based on the New York Heart Association classification could be complemented by a new one staging the progression of MVD in A, B, C and $\mathrm{D}$. Then, group $\mathrm{A}$ was represented by those dogs that have hereditary predisposition but no signs of MVD and group B were those with MVD but no signs of CHF. On the other hand, group $\mathrm{C}$ was composed by dogs with MVD and signs of $\mathrm{CHF}$ and those included in group $\mathrm{D}$ present signs of $\mathrm{CHF}$ and were refractory to therapy (Atkins et al., 2009).

This new classification aims to help in the identification and provide a consensus about the treatment of the MVD according its stage, which was discussed by Atkins and Häggström (2012).

In a study of Schober and others (2010), some echocardiographic variables that could be used as markers of the onset of CHF in dogs with MVD were proposed, demonstrating the importance of new methods that could help the early identification of CHF. Even with the wide number of techniques available for identification of $\mathrm{CHF}$, there are few studies demonstrating the use of mathematical methods to evaluate the development of CHF in dogs with MVD.

The aim of this study was to evaluate the clinical, radiographic and echocardiographic presence of CHF in dogs with MVD in combination with discriminant analysis as a complementary tool to help with the identification of CHF in the groups evaluated.

\section{MATERIAL AND METHODS}

The study was performed on client-owned dogs presented to the Cardiology service of the Veterinary Hospital of the University. Prior to enrollment, informed consent was obtained from each owner. As inclusion criteria, only small breeds were selected for this study. All dogs received a physical examination and thoracic radiographs (right lateral, left, and ventraldorsal). Radiographs were evaluated for signs of CHF (enlarged left atrium, pulmonary venous congestion, perihilar or caudal lung lobe edema) and divided into three groups (Schober et al., 2010), with group I composed of healthy animals (control), group II of animals with MVD but no CHF and group III of animals with MVD and signs of CHF.

Echocardiography was performed in all animals without sedation using a Doppler echocardiography workstation (MyLab 40, Esaote $^{\circledR}$ ), with a phased array 3-11 $\mathrm{MHz}$ sector transducer and simultaneous 
electrocardiographic monitoring. All examinations were recorded for off-line analysis. All the images were obtained and measured by a single echocardiographer with experience in clinical research (R.A.L.M)

Dogs were positioned in right and left lateral recumbency and the electrocardiographic electrodes were positioned on the limbs. Twodimensional images were obtained in a right parasternal long axis view of the mitral valve (MV) and left ventricle (LV), a parasternal short axis view at the level of the papillary muscles, and at the level of the LA and aortic root (Ao). The LV M-mode was obtained from a twodimensional image of the right parasternal short axis view just below the MV. The left parasternal apical four and five chamber views were evaluated with the aid of color mapping, pulsed wave Doppler and continuous wave Doppler. Blood flow velocities were obtained from the aorta, pulmonary artery and right and left atrioventricular valves. Isovolumetric relaxation time was evaluated using pulsed wave Doppler in a left apical 5-chamber view.

The following measurements were made at enddiastole and end-systole from M-mode images: LV wall thickness, LV internal diameter, and interventricular septal thickness. For each variable, 3 measurements were performed in 3 consecutive cardiac cycles and the average obtained.

The mitral regurgitation area (MRA), vena contracta (VC) diameter and regurgitant fraction of proximal isovelocity surface area (RF PISA) were obtained from color flow mapping (Doppler) from the left apical four-chamber view, as described by previous studies (Kittleson and Brown, 2003; Muzzi et al., 2003; Gouni et al., 2007). For obtaining RF PISA, the color flow Doppler jet of mitral valve regurgitation was first identified with optimal gain setting. Then, the mitral valve region was magnified to identify the flow convergence region proximal to the regurgitant orifice, as described by Gouni et al. (2007).

The variables left atrium/aortic root ratio (LA/Ao), peak E wave velocity (E Pvel), mitral A wave and E/A ratio, ratio of MRA/LA, VC, Doppler cardiac index (Doppler CI) and endsystolic volume (ESV) were recorded.
Acquisition of echocardiographic images as well as measurements of the variables was performed as previously described (Bonagura and Schober, 2009; Boon, 2011).

Regarding statistical analyses a descriptive analysis for the variables weight, sex and age was performed, with frequency distribution among the 3 different groups, obtaining the median and range for each variable. Weight, body surface area (BSA), age, Ao, LA, LA/Ao ratio, ESV; MRA/LA ratio, E Pvel, VC, RF PISA and Doppler CI were compared between the 3 different groups by variance analysis, with a Tukey test used for post hoc analysis $(P<0.05)$. Then, the variables weight, BSA, Ao, LA/Ao, MRA/LA, VC and RF PISA were selected and evaluated by discriminant analysis (Ferreira, 2011). All statistical analyses were performed using the SAS statistical package (Statistical..., 2006).

\section{RESULTS}

A total of 81 dogs met the inclusion criteria. Breeds included were Poodle (miniature and toy), Miniature Schnauzer, Cocker Spaniel, Chihuahua, Fox Terrier, Dachshund, Doberman, Yorkshire and Brazilian Terrier. Median age was 11 (6 - 18 years), and median weight was 5.20 (2.0 - $14.3 \mathrm{~kg})$; 32 were females (39.5\%) and 49 were males $(60.5 \%)$.

Weight, BSA, age, and Doppler CI were not different $(\mathrm{P}>0.05)$ between the three studied groups (Table 1$)$. In the same way, there was no difference $(\mathrm{P}>0.05)$ for breed and gender among the three groups evaluated.

There were differences $(\mathrm{P}<0.05)$ for the variables LA, LA/Ao, ESV, MRA/LA, E Pvel, VC and RF PISA between the three groups (Table 2). For the echocardiographic variables LA, LA/Ao, ESV and E Pvel, the animals in group III had higher values $(\mathrm{P}<0.05)$ when compared with those in groups I and II, but groups I and II did not differ from each other for these parameters $(\mathrm{P}>0.05)$. The animals in the three groups also differed for the variables MRA/LA, RF PISA and VC $(\mathrm{P}<0.05)$, with those in group I having the lowest values and those in group III the highest values. 
Silva et al.

Table 1. Medians and ranges for weight and age, and mean values \pm standard deviations in BSA and Doppler CI for 81 animals in three different groups

\begin{tabular}{|c|c|c|c|c|c|}
\hline \multirow{2}{*}{ Variables $^{\mathrm{a}}$} & \multicolumn{3}{|c|}{ Group $^{b}$} & \multirow{2}{*}{$\begin{array}{c}\text { Global } \\
\text { mean }\end{array}$} & \multirow{2}{*}{$P$ value $^{\mathrm{c}}$} \\
\hline & $\mathrm{I}$ & II & III & & \\
\hline Weight (kg) & $5.0(2.8-14)$ & $5.4(2-14)$ & $5.9(2.1-14.3)$ & $5.2(2-14,3)$ & 0.8697 \\
\hline Age (years) & $11.5(7-14)$ & $11.0(6-15)$ & $12.0(6-18)$ & $11.0(6-18)$ & 0.1427 \\
\hline $\operatorname{BSA}\left(\mathrm{m}^{2}\right)$ & $0.33 \pm 0.11$ & $0.32 \pm 0.11$ & $0.34 \pm 0.12$ & $0.33 \pm 0.11$ & 0.8640 \\
\hline Ao $(\mathrm{cm})$ & $1.46 \pm 0.29$ & $1.51 \pm 0.29$ & $1.50 \pm 0.32$ & $1.50 \pm 0.30$ & 0.8020 \\
\hline Doppler CI $\left(\mathrm{L} / \mathrm{min} / \mathrm{m}^{2}\right)$ & $3.17 \pm 1.16$ & $3.39 \pm 1.14$ & $2.90 \pm 0.94$ & $3.17 \pm 1.09$ & 0.2173 \\
\hline
\end{tabular}

${ }^{a}$ BSA: Body surface area; Ao: Aortic diameter; Doppler CI: Doppler cardiac index.

${ }^{\mathrm{b}}$ Group I: healthy animals; Group II: Animal with MVD but no CHF; Group III: Animals with MVD and signs of CHF.

${ }^{\mathrm{c}}$ Not significant with the use of $\mathrm{F}$ test $(P>0.05)$.

Table 2. Mean values \pm standard deviation of LA, LA/Ao, ESV, MRA/LA, E Pvel, VC and RF PISA for 81 animals in three different groups

\begin{tabular}{cccccc} 
Variables $^{\mathrm{a}}$ & \multicolumn{3}{c}{ Group $^{\mathrm{b}}$} & \multirow{2}{*}{ Global mean } & $P$ value \\
\cline { 2 - 4 } & $\mathrm{I}$ & $\mathrm{II}$ & $\mathrm{III}$ & & \\
\hline LA $(\mathrm{cm})$ & $1.513 \pm 0.269 \mathrm{~b}$ & $1.738 \pm 0.399 \mathrm{~b}$ & $2.467 \pm 0.667 \mathrm{a}$ & $1.193 \pm 0.620$ & $<0.01$ \\
LA/Ao (cm) & $1.034 \pm 0.137 \mathrm{~b}$ & $1.154 \pm 0.165 \mathrm{~b}$ & $1.651 \pm 0.443 \mathrm{a}$ & $1.290 \pm 0.384$ & $<0.01$ \\
ESV (ml) & $6.117 \pm 5.434 \mathrm{~b}$ & $7.729 \pm 4.912 \mathrm{~b}$ & $12.324 \pm 7.104 \mathrm{a}$ & $8.863 \pm 6.312$ & $<0.01$ \\
MRA/LA (\%) & $0.000 \pm 0.000 \mathrm{c}$ & $47.090 \pm 13.999 \mathrm{~b}$ & $65.480 \pm 10.722 \mathrm{a}$ & $41.590 \pm 27.498$ & $<0.01$ \\
E Pvel (m/s) & $0.517 \pm 0.106 \mathrm{~b}$ & $0.577 \pm 0.103 \mathrm{~b}$ & $0.676 \pm 0.150 \mathrm{a}$ & $0.595 \pm 0.135$ & $<0.01$ \\
VC & $0.000 \pm 0.000 \mathrm{c}$ & $0.220 \pm 0.073 \mathrm{~b}$ & $0.330 \pm 0.102 \mathrm{a}$ & $0.200 \pm 0.146$ & $<0.01$ \\
RF PISA (\%) & $0.000 \pm 0.000 \mathrm{c}$ & $39.52 \pm 14.747 \mathrm{~b}$ & $68.380 \pm 16.153 \mathrm{a}$ & $39.380 \pm 29.086$ & $<0.01$ \\
\hline
\end{tabular}

${ }^{a}$ Means followed by different letters in the line differ significantly by Tukey test $(P<0.05)$. LA: left atrium; Ao: aortic diameter; ESV: end systolic volume; MRA: mitral regurgitation area; E Pvel: peak E wave velocity; VC: Vena contracta; RF PISA: regurgitant fraction of proximal isovelocity surface area.

${ }^{\mathrm{b}}$ Group I: healthy animals; Group II: Animals with MVD but no CHF; Group III: Animals with MVD and signs of CHF.

A linear discriminant function was established for each of the three groups of animals according to the values of some parameters obtained at echocardiography, as shown below:

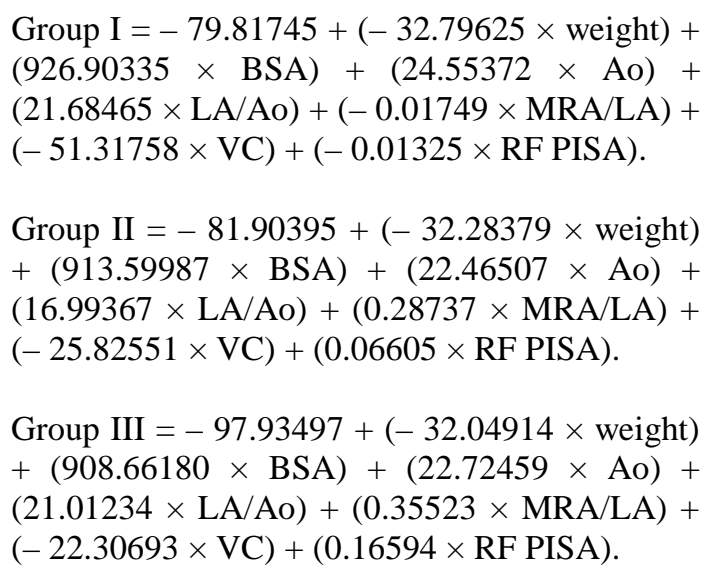

By using these models of linear discriminant function, the classification methods proposed in this study resulted in a statistical confidence of 90.4\% (with only $9.6 \%$ misclassification). Only 9/81 animals were classified inappropriately. Of these 9 animals, 6/34 animals classified in group II should have been classified as group III and 3/27 animals classified in group III should have been classified as group II.

The distance between the three different groups (similarity diagram) is shown in Figure 1. It was observed by means of this analysis that group I presented the highest multidimensional distance when compared with other groups. Thus, for the variables evaluated in this study, animals in group II and III showed major similarities when compared to group I. 


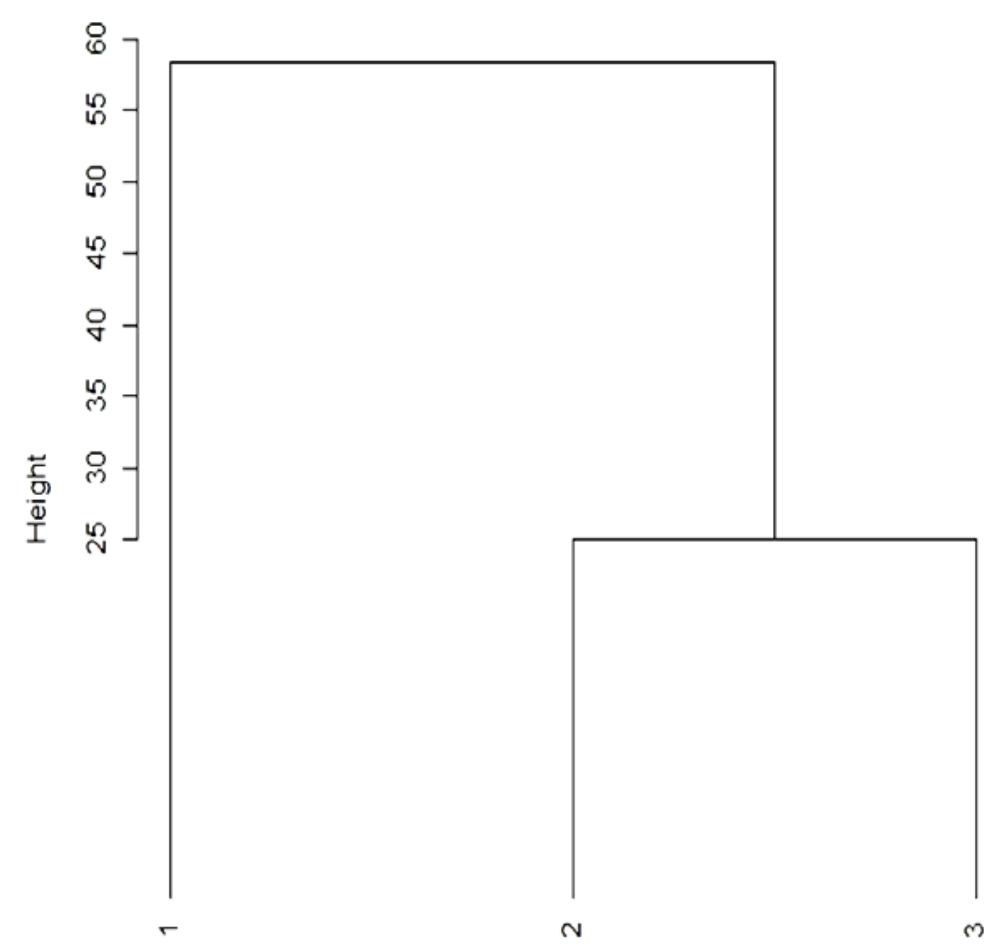

Figure 1. Similarity diagram (Dendogram) between the three different groups of animals. The diagram shows the difference between group 1 and the other groups, visually illustrating the significant distance between each group.

\section{DISCUSSION}

The statistical method applied in this study was demonstrated to be feasible, and a reliable and useful tool to help in the detection of $\mathrm{CHF}$ in dogs with MVD.

Statistical analyses were performed with all echocardiographic variables, however for this study we selected only those that offered greater statistical reliability, and presented reduced error rates for classification of the animals after being previously tested statistically.

The lack of differences in weight and BSA between the three study groups $(P>0.05)$ can be explained by the fact that only small dog breeds were selected, which also accounts for the similar Ao.

Animals with CHF (group III) had a larger LA diameter $(P<0.05)$ compared with the other groups, which were statistically similar to each other. This fact is reported in the literature as a result of MR worsening, leading to the onset of signs of CHF (Carlsson et al., 2009). Moreover, the severity of MR is a major determinant of LA size in small animals (Kittleson and Brown, 2003). The LA/Ao ratio was greater in group III compared with the other groups; this could be justified by the fact that this ratio is directly influenced by the increase in the left atrium. Thus, as the Ao was similar among the three groups, this ratio was directly influenced only by differences in LA size, and since the animals in group III were those that had $\mathrm{CHF}$, we can infer that the LA/Ao ratio is directly related to severity of MR (Borgarelli et al., 2008). In addition, one study demonstrated that the LA/Ao ratio was correlated significantly with the regurgitation fraction obtained by PISA (Gouni et al., 2007). In our study, the RF PISA showed higher values for group III $(68.380 \% \pm 16.153 \%)$ and the literature reports that values greater than $50 \%$ should be considered significant in cases of moderate to severe MR (Gouni et al., 2007), with values greater than $75 \%$ considered severe in small dogs (Kittleson and Brown, 2003). Furthermore, it was demonstrated in a study that the PISA method has excellent viability, showing 
agreement with calculations obtained by Doppler flow (Choi et al., 2004).

Regarding MRA/LA, the animals in group III presented higher values when compared to animals without $\mathrm{CHF}$ due to the greater severity of the MVD with a greater mitral regurgitation. In addition, one study showed a good correlation between MRA/LA and severe MR, despite the limitations of this method (Muzzi et al., 2003). Another study demonstrated that MRA and the intensity of the heart murmur were significant predictors of an increase in LA diameter (Olsen et al., 2003).

The E Pvel is dependent on the regurgitant volume and left atrial pressure, thus increasing LA/Ao, and E Pvel can be considered suggestive of overloading and increased left atrial pressure. One study demonstrated that animals with E Pvel $>1.2 \mathrm{~m} / \mathrm{s}$ have a lower survival rate (Borgarelli et al., 2008). In our study, the average for this variable was $<1.2 \mathrm{~m} / \mathrm{s}$ in all groups.

Color Doppler flow mapping represents an important technique for the recognition and evaluation of MR. Thus, it was demonstrated in sheep that the VC obtained by color Doppler could predict the severity of MR (Zhou et al., 1997). This good correlation between the VC and MR has also been described in humans (Hall et al., 1997). In studies of three-dimensional echocardiography in humans, VC was also a representative index of the severity of MR (Little et al., 2008; Yosefy et al., 2009). In our study there were differences between the studied groups, with group III (with CHF) presenting the highest values for the VC. Thus, the value of this variable changed according to the worsening of the MR and consequently with the onset of CHF. However, in dogs with MVD, more studies are needed to elucidate the true value of the VC to predict the severity of MR and its relation to the presence of CHF.

A linear discriminant function analysis was performed according to the above-mentioned variables, and animals were classified as healthy (group I) without CHF (group II) or with $\mathrm{CHF}$ (group III). This classification according to the presence or absence of CHF, proposed by Schober et al. (2010) helps to reduce the subjectivity of classification based only on findings of MVD and reduces the error rate in the classification of animals.

The functions validated in this study showed highly significant statistical correlations with the clinical status of the dogs. These equations present a great potential for use in routine of veterinary cardiology, since they are easy to interpret, requiring only that the values for each variable found during the examination be inserted. Thus, associated with clinical, radiographic and echocardiographic findings, the mathematical model aids in correct classification of the patient.

The fact that 9 animals were classified incorrectly in groups (six in group II and three in group III), is explained by the fact that the original classification was based on clinical findings, radiographic imaging and the history of the animal, as well as on echocardiography, so the results may reflect the limitations of this qualitative analysis. However, the found error rate is small, demonstrating that the equations generated can be used in conjunction with qualitative methods to obtain the correct group classification of the animal.

The discriminant analysis has been used in several studies in the field of human medical cardiology. For example, O'Connor et al. (1999) with the aim to identify risk factors associated with in-hospital mortality among patients undergoing percutaneous coronary interventions demonstrated that with the use of multivariate prediction/analysis the calculation of the risk of in-hospital mortality after a percutaneous coronary intervention was feasible and accurate, and may be useful for patient counseling and for improvement of quality purposes. In another study, Matheny et al. (2005) evaluated the discrimination and calibration of mortality risk prediction models (logistic regression) in interventional cardiology and obtained positive results with the use of this method.

Some limitations to this study should be discussed, such as the radiographic examination, which may be influenced by the examiner's experience in classifying the findings, thus reducing the sensitivity of the test in the case of classifying animals regarding the presence or absence of CHF (Schober et al., 2010). Similarly, the echocardiographic variables can be 
affected by the experience of the examiner and also according to the type of equipment and transducer used. We can also point out that, although in a limited way, discriminant analysis is a promising parameter to help in the classification of $\mathrm{CHF}$, being necessary improvement and further studies on the subject.

In our study, the MRA/AE ratio was used to reduce the influence of left atrial size, as reported in a previous study (Muzzi et al., 2003). However, this ratio can be affected by various factors such as arterial blood pressure, LA pressure, pulse repetition frequency and gain of the echocardiographic equipment (Gouni et al., 2007). In the present study, blood pressure was obtained in all animals.

Regarding RF PISA, it can often be difficult to obtain the precise location of the hole and shape of the converging flow (Gouni et al., 2007). This difficulty could alter the values of this variable.

The VC is an index already used in humans to evaluate MR. However, it requires that the images and measurements be obtained with great accuracy, since small variations in values can lead to large percentage errors and misclassification of MR (Zoghbi et al., 2003).

\section{CONCLUSIONS}

Despite some limitations, this study contributes to a better classification of animals. Furthermore, it is an easy method to perform in the context of veterinary cardiology, which renders it suitable for use in routine veterinary cardiology along with clinical, radiographic and echocardiographic evaluations. When added to the qualitative measures, the quantitative ones offered by these equations can contribute to greater reliability in classifying animals with MVD, either with or without the presence of $\mathrm{CHF}$, facilitating therapeutic management of the patients.

\section{ACKNOWLEDGEMENTS}

The authors wish to thank Conselho Nacional de Desenvolvimento Científico e Tecnológico (CNPq), Coordenação de Aperfeiçoamento de Pessoal de Nível Superior (CAPES) and Fundação de Amparo à Pesquisa do Estado de Minas Gerais (FAPEMIG), for their support.

\section{REFERENCES}

ABBOTT, J.A. Acquired valvular disease. In: TILLEY, L.P.; SMITH Jr., F.W.K.; OYAMA, M.A.; SLEEPER, M.M. (Eds). Manual of Canine and Feline Cardiology. 4th Edn. St Louis/Missouri, United State of America: Saunders Elsevier, 2008. p.110-131.

ATKINS, C.; BONAGURA, J.D.; ETTINGER, S. et al. Guidelines for the diagnosis and treatment of canine chronic valvular heart disease. J. Vet. Intern. Med., v.23, p.1142-1150, 2009.

ATKINS, C.E.; HÄGGSTRÖM, J. Pharmacology management of myxomatous mitral valve disease in dogs. J. Vet. Cardiol., v.14, p.165-184, 2012.

BONAGURA, J.D.; SCHOBER, K.E. Can ventricular function be assessed by echocardiography in chronic canine mitral valve disease? J. Small Anim. Pract., v.50, p.12-24, 2009.

BOON, J.A. Evaluation of size, function, and hemodynamics. In: BOON, J.A. (Ed). Veterinary echocardiography. 2.ed. Ed. Iowa, USA: WileyBlackwell, 2011. p.153-247.

BORGARELLI, M.; BUCHANAN, J.W. Historical review, epidemiology and natural history of degenerative mitral valve disease. J. Vet. Cardiol., v.14, p.93-101, 2012.

BORGARELLI, M.; HÄGGSTRÖM, J. Canine degenerative myxomatous mitral valve disease: natural history, clinical presentation and therapy. Vet. Clin. North Am. Small Anim. Pract., v.40, p.651-663, 2010.

BORGARELLI, M.; SAVARINO, P.; CROSARA, S. et al. Survival characteristics and prognostic variables of dogs with mitral regurgitation attributable to myxomatous valve disease. J. Vet. Intern. Med., v.22, p.120-128, 2008.

BORGARELLI, M.; ZINI, E.; D’AGNOLO, G. et al. Comparison of primary mitral valve disease in German Shepherd dogs and in small breeds. J. Vet. Cardiol., v.6, p.27-34, 2004.

CARLSSON, C.; HÄGGSTRÖM, J.; ERIKSSON, A. et al. Size and shape of right heart chambers in mitral valve regurgitation in small-breed dogs. J. Vet. Intern. Med., v.23, p.1007-1013, 2009.

CHOI, H.; LEE, K.; LEE, H. et al. Quantification of mitral regurgitation using proximal isovelocity surface area method in dogs. J. Vet. Sci., v.5, p.163-171, 2004.

ENRIQUEZ-SARANO, M.; AKINS, C.W.; VAHANIAN, A. Mitral regurgitation. Lancet., v.373, p.1382-1394, 2009.

FERREIRA, D.F. Sisvar: a computer statistical analysis system. Cienc. Agrotec., v.35, p.1039-1042, 2011. 
GOUNI, V.; SERRES, F.J.; POUCHELON, J.L. et al. Quantification of mitral valve regurgitation in dogs with degenerative mitral valve disease by use of the proximal isovelocity surface area method. J. Am. Vet. Med. Assoc., v.231, p.399-406, 2007.

HALL, S.A.; BRICKNER, M.E.; WILLETT, D.L. et al. Assessment of mitral regurgitation severity by Doppler color flow mapping of the vena contracta. Circulation., v.95, p.636-642, 1997.

HÄGGSTRÖM, J.; HÖGLUND, K.; BORGARELLI, $\mathrm{M}$. An update on treatment and prognostic indicators in canine myxomatous mitral valve disease. J. Small Anim. Pract., v.50, p.25-33, 2009.

HYUN, C. Mitral valve prolapse in Cavalier King Charles Spaniel: A review and case study. J. Vet. Sci., v.6, p.67-73, 2005.

KITTLESON, M.D.; BROWN, W.A. Regurgitant fraction measured by using the proximal isovelocity surface area method in dogs with chronic myxomatous mitral valve disease. J. Vet. Intern. Med., v.17, p.8488, 2003.

LEWIS, T.; SWIFT, S.; WOOLLIAMS, J.A.; BLOTT, S. Heritability of premature mitral valve disease in Cavalier King Charles spaniels. Vet. J., v.188, p.73-76, 2011.

LITTLE, S.H.; PIRAT, B.; KUMAR, R. et al. ThreeDimensional color Doppler echocardiography for direct measurement of vena contracta area in mitral regurgitation in vitro validation and clinical experience. JACC Cardiovasc. Imaging., v.1, p.695704, 2008.

LJUNGVALL, I.; AHLSTROM, C.; HÖGLUND, K. et al. Use of signal analysis of heart sounds and murmurs to assess severity of mitral valve regurgitation attributable to myxomatous mitral valve disease in dogs. Am. J. Vet. Res., v.70, p.604-613, 2009.

MATHENY, M.E.; OHNO-MACHADO, L.; RESNIC, F.S. Discrimination and calibration of mortality risk prediction models in interventional cardiology. J. Biomed. Inform., v.38, p.367-375, 2005.
MUZZI, R.A.L.; ARAÚJO, R.B.; MUZZI, L.A.L. et al. Regurgitant jet area by Doppler color flow mapping: quantitative assessment of mitral regurgitation severity in dogs. J. Vet. Cardiol., v.5, p.33-38, 2003.

OLSEN, L.H.; MARTINUSSEN, T.; PEDERSEN, H.D. Early echocardiographic predictors of myxcomatous mitral valve disease in dachshunds. Vet. Record., v.152, p.293-297, 2003.

O'CONNOR, G.T.; MALENKA, D.J.; QUINTON, H. et al. Multivariate prediction of in-hospital mortality after percutaneous coronary interventions in 19941996. Northern New England Cardiovascular Disease Study Group. J. Am. Coll. Cardiol., v.34, p.681-691, 1999.

STATISTICAL Analysis Sistem - SAS, SAS User's Manual, Statistical Analyses System Institute, Cary, NC, 2006.

SCHOBER, K.E.; HART, T.M.; STERN, J.A. et al. Detection of congestive heart failure in dogs by Doppler echocardiography. J. Vet. Intern. Med., v.24, p.1358-1368, 2010.

YOSEFY, C.; HUNG, J.; CHUA, S. et al. Direct measurement of vena contracta area by real-time 3dimensional echocardiography for assessing severity of mitral regurgitation. Am. J. Cardiol., v.104, p.978983, 2009.

ZHOU, X.; JONES, M.; SHIOTA, T. et al. Vena contracta imaged by Doppler color flow mapping predicts the severity of eccentric mitral regurgitation better than color jet area: a chronic animal study. $J$. Am. Coll. Cardiol., v.30, p.1393-1398, 1997.

ZOGHBI, W.A.; ENRIQUEZ-SARANO, M.; FOSTER, E. et al. Recommendations for evaluation of the severity of native valvular regurgitation with twodimensional and Doppler echocardiography. J. Am. Soc. Echocardiogr., v.16, p.777-802, 2003. 